\title{
Effects caused by the internal heat exchanger at the low temperature cycle in a cascade refrigeration plant
}

\author{
Rodrigo Llopis ${ }^{1, *}$, Carlos Sanz-Kock1, Ramón Cabello, Daniel Sánchez", \\ Laura Nebot-Andrés ${ }^{1}$, Jesús Catalán-Gil ${ }^{1}$
}

${ }^{1}$ Jaume I University, Dep. of Mechanical Engineering and Construction, Campus de Riu Sec s/n E-12071, Castellón, Spain

*Corresponding author: R. Llopis (rllopis@uii.es), Phone: +34 964 72 8136; Fax: +34 964728106.

\begin{abstract}
This work analyses and quantifies the effects caused by the use of an internal heat exchanger (IHX) at the $\mathrm{CO}_{2}$ subcritical cycle in an $\mathrm{HFC} 134 \mathrm{a} / \mathrm{CO}_{2}$ cascade refrigeration plant that incorporates a gas-cooler at the exit of the low temperature compressor. Previous theoretical and experimental studies showed that the $\mathrm{IHX}$ reduces the refrigeration capacity and COP of the subcritical cycle, however, it has been seen that it also lowers the heat to be rejected at the condenser. This reduction, when the cycle is a part of a cascade system, allows reducing the heat load of the high temperature cycle, modifying the working conditions of the cascade plant. The modifications result in an increment of the overall coefficient of performance of the cascade system. The analysis here presented is based on the evaluation of an experimental $\mathrm{HFC134a/CO} 2$ refrigeration plant, which has been analysed with and without internal heat exchanger in an evaporating temperature range from -40 to $-30^{\circ} \mathrm{C}$ and in a condensing one from 30 to $50^{\circ} \mathrm{C}$. The plant incorporates a gas-cooler at the exit of the $\mathrm{CO}_{2}$ compressor. The experimental results confirm that the IHX slightly reduces the cooling capacity but it can increment the overall COP up to $3.7 \%$.
\end{abstract}

\section{KEYWORDS}

$\mathrm{CO}_{2}$; subcritical; internal heat exchanger; cascade; experimental 


\section{HIGHLIGHTS}

- The effects of an IHX in a $\mathrm{CO}_{2}$ subcritical cycle with gas-cooler on a $\mathrm{HFC} 134 \mathrm{a} / \mathrm{CO}_{2}$ cascade are analysed.

- The IHX reduces the cooling capacity between 1.1 to $2.4 \%$

- The IHX reduces the heat transfer in cascade heat exchanger between 4.4 to $5.5 \%$

- $\quad$ The IHX increases the COP of the cascade system up to $3.7 \%$ 


\begin{tabular}{|c|c|}
\hline casc & Cascade heat exchanger \\
\hline COP & Coefficient of performance \\
\hline$h$ & Specific enthalpy (kJ/kg) \\
\hline HT & High temperature \\
\hline$H X$ & Heat exchanger \\
\hline$I H X$ & Internal heat exchanger \\
\hline$L T$ & Low temperature \\
\hline$\dot{m}$ & Refrigerant mass flow rate $(\mathrm{kg} / \mathrm{s})$ \\
\hline N & Compressor speed (rpm) \\
\hline$P$ & Pressure (bar) \\
\hline$P_{c}$ & Electric power consumption (kW) \\
\hline$q_{0}$ & Specific cooling capacity (kJ/kg) \\
\hline$q_{K}$ & Difference of specific enthalpy in condenser $(\mathrm{kJ} / \mathrm{kg})$ \\
\hline$\dot{Q}_{\text {casc }}$ & Heat transfer rate in cascade heat exchanger (kW) \\
\hline$\dot{Q}_{I H X}$ & Heat transfer rate in internal heat exchanger (kW) \\
\hline$\dot{Q}_{K}$ & Heat transfer rate in condenser $(\mathrm{kW})$ \\
\hline$\dot{Q}_{O}$ & Cooling capacity (kW) \\
\hline S & Heat transfer area $\left(\mathrm{m}^{2}\right)$ \\
\hline$T$ & Temperature $\left({ }^{\circ} \mathrm{C}\right)$ \\
\hline $\bar{U}$ & Averaged overall heat transfer coefficient $\left(\mathrm{W} / \mathrm{m}^{2} \cdot \mathrm{K}\right)$ \\
\hline$\dot{V}_{G}$ & Compressor displacement (m3/s) \\
\hline \multicolumn{2}{|c|}{ GREEK SYMBOLS } \\
\hline$\Delta$ & Variation \\
\hline$\eta_{v}$ & Volumetric efficiency \\
\hline$\varepsilon$ & Thermal effectiveness \\
\hline$v$ & specific volume (m³/kg) \\
\hline \multicolumn{2}{|l|}{ SUBSCRIPTS } \\
\hline C & cascade heat exchanger \\
\hline dis & Compressor discharge \\
\hline
\end{tabular}




$\begin{array}{cl}\text { env } & \text { Environment } \\ \text { exp } & \text { Expansion valve } \\ g & \text { Glycol, secondary fluid in evaporator } \\ \text { gc } & \text { Gas cooler } \\ H & \text { High temperature cycle } \\ \text { i } & \text { Inlet } \\ \text { ihx } & \text { Internal heat exchanger } \\ \text { K } & \text { Condensation } \\ \text { L } & \text { Low temperature cycle } \\ \text { O } & \text { Evaporation } \\ \text { O } & \text { Outlet } \\ r & \text { Refrigerant } \\ \text { suc } & \text { Compressor suction } \\ \text { W } & \text { Water, secondary fluid in condenser }\end{array}$




\section{Introduction}

The new rules for the commercial refrigeration sector established by the F-Gas regulation in Europe [1], meaning the practical end of use of the R404A or R507A in medium and large centralized refrigeration systems from 2022 on, have expanded the use of cascade refrigeration systems using $\mathrm{CO}_{2}$ as low temperature refrigerant, especially in supermarket refrigeration for low temperature [2]. Cecchinato et al. discussed the best options of using natural refrigerants in supermarket refrigeration [3] and integrating them with HVAC systems. Focussing on cascade systems with $\mathrm{CO}_{2}$ as low temperature refrigerant, Sharma et al. [4] and Llopis et al. [5], using a theoretical approach, concluded that cascade systems using $\mathrm{CO}_{2}$ as low temperature refrigerant are a good alternative to the current R404A direct expansion systems. They can present small reductions in COP but with high reductions of the Total Warming Equivalent Impact regards the classical systems, but with new designs, such as high efficient compressors or electronic expansion valves, they can overcome the firsts. This was experimentally verified by da Silva et al. [6] in a pilot supermarket plant, where a $\mathrm{R} 404 \mathrm{~A} / \mathrm{CO}_{2}$ cascade plant offered $22.3 \%$ reduction of electricity consumption during a year of operation regards a conventional R404A direct expansion configuration.

Since the low temperature level of commercial refrigeration is around $-30^{\circ} \mathrm{C}$ to maintain frozen products, $\mathrm{CO}_{2}$ compressor manufacturers recommend the use of an internal heat exchanger $(\mathrm{IHX})$ in the low temperature cycle to increase the suction temperature of the compressor. In fact, they recommend operating the compressors with a minimum superheat at suction of $20 \mathrm{~K}$ to avoid problems related with lubrication and to extend the useful life of the compressor. The IHX allows obtaining this increase in suction temperature providing at the same time a small subcooling of the liquid $\mathrm{CO}_{2}$ at the exit of the condenser. This element has been widely analysed for plants working with HFC refrigerants [7-9] and for plants working with $\mathrm{CO}_{2}$ in transcritical conditions $[10,11]$. In general, its use is beneficial if the refrigerant has high heat capacity. For $\mathrm{CO}_{2}$ in transcritical conditions its use has been experimentally corroborated to increase the energy performance of the plant.

However, the use of the $\mathrm{IHX}$ in $\mathrm{CO}_{2}$ subcritical cycles has drawn little attention up to the moment. The unique available studies are the ones presented by Zhang et al. [12] and Llopis et al. [13]. Zhang et al. [12] evaluated theoretically the effect of the use of the $\mathrm{IHX}$ in $\mathrm{CO}_{2}$ transcritical and subcritical cycles. For $\mathrm{CO}_{2}$ subcritical cycles, they considered evaporating temperatures from -20 to $-10{ }^{\circ} \mathrm{C}$ and condensing temperatures from 10 to $20^{\circ} \mathrm{C}$. Theoretically, they observed that the use of the IHX slightly lowered the COP and the capacity of the system, concluding that its use is not convenient for subcritical cycles. This theoretical results were corroborated experimentally by Llopis et al. [13] in a $\mathrm{CO}_{2}$ subcritical cycle working with a semihermetic compressor and a gas-cooler at the exit of the compressor. For an evaluation range of -40 to $-25^{\circ} \mathrm{C}$ of evaporating temperature and of -15 to $0{ }^{\circ} \mathrm{C}$ of condensing temperature, they measured 
reductions in the capacity provided by the subcritical cycle ranging from $3.5 \%$ at $-40{ }^{\circ} \mathrm{C}$ to $3.7 \%$ at $-25^{\circ} \mathrm{C}$. They also measured reductions in the COP varying from -1.58 to $-3.29 \%$ at $-25^{\circ} \mathrm{C}$ but small increases up to $0.45 \%$ at $-40^{\circ} \mathrm{C}$. This experimental results are in agreement with the theoretical predictions of Zhang et al. [12], who does not recommend the use of the IHX in subcritical cycles from the point of view of energy efficiency. But as pointed out theoretically by Llopis et al. [13], the IHX also reduces the heat to be released in the condenser of the plant, and therefore, when the subcritical cycle is used as a part of a cascade system its effect must be analysed considering the whole cascade system. With a simplified approach, they pointed out that the reduction of the heat to be transferred in the cascade heat exchanger could provide increases of the overall COP of a cascade system, with a maximum increase of $3 \%$.

Accordingly, this paper is devoted to present and analyse the global effects of the use of an IHX in the subcritical cycle in a whole $\mathrm{HFC} 134 \mathrm{a} / \mathrm{CO}_{2}$ cascade system. Using the previous experimental data presented by Llopis et al. [13], this paper focuses on the modifications induced in the cascade heat exchanger and in the high temperature cycle $(\mathrm{HT})$ of the cascade system. First, we summarize the effects of the $\mathrm{IHX}$ in the $\mathrm{CO}_{2}$ subcritical cycle. Then, we detail the modifications induced in the cascade heat exchanger and in the HT cycle. Next, we present the experimental COP of the overall cascade system in all tested conditions. Finally, we compare the operation of the plant with and without the IHX in the best performing energy conditions of the plant.

\section{Experimental plant and measurement system}

The experimental evaluation has been carried out with a $\mathrm{HFC134a/} / \mathrm{CO}_{2}$ cascade refrigeration plant, presented previously by Sanz-Kock et al. [14], whose main scheme is detailed in Figure 1.

The subcritical cycle uses a semihermetic compressor with a displacement of $3.48 \mathrm{~m}^{3} \cdot \mathrm{h}^{-1}$ at $1450 \mathrm{rpm}$ and a nominal power of $1.5 \mathrm{~kW}$ (at evaporation of $-35^{\circ} \mathrm{C}$ and condensation of $-10{ }^{\circ} \mathrm{C}$ ) and incorporates a finned-tube gas-cooler with $0.6 \mathrm{~m}^{2}$ heat transfer area in the refrigerant side driven with a fan with nominal electricity consumption of $75 \mathrm{~W}$. Two brazed plate heat exchangers with a total heat transfer area of 3.52 $\mathrm{m}^{2}$ are used as cascade heat exchanger, a $0.096 \mathrm{~m}^{2}$ brazed plate heat exchanger as $\mathrm{HXX}$, and a $2.39 \mathrm{~m}^{2}$ brazed plate heat exchanger as evaporator. The expansion valve is electronic working as thermostatic control. A secondary fluid loop using an $84 \%$ by vol. tyfoxit-water mixture provides the cooling load to the plant. More details about the secondary loop can be found in Llopis et al. [15].

The high temperature cycle, working with $\mathrm{HFC134a,} \mathrm{is} \mathrm{driven} \mathrm{by} \mathrm{a} \mathrm{semihermetic} \mathrm{compressor} \mathrm{with}$ displacement of $32.66 \mathrm{~m}^{3} \cdot \mathrm{h}^{-1}$ at $1450 \mathrm{rpm}$ and nominal power of $3.7 \mathrm{~kW}$ (at evaporation of $-35^{\circ} \mathrm{C}$ and condensation of $30^{\circ} \mathrm{C}$ ). It is a variable speed compressor operated with an inverter drive. A brazed plate 
heat exchanger of $2.39 \mathrm{~m}^{2}$ is used as condenser and two electronic expansion valves working as thermostatic control the evaporating process in the cascade heat exchanger. The heat dissipation in condenser is done with a loop working with water [16].

The experimental plant is fully instrumented. The location of sensors is described in Figure 1. It incorporates 29 T-type thermocouples with an uncertainty of $\pm 0.5^{\circ} \mathrm{C} .7$ pressure gauges are used in the subcritical cycle ( 3 of $0-60$ bar \pm 0.18 bar, 4 of $0-100$ bar \pm 0.3 bar) and 4 in the HFC134a cycle (2 of 0-10 bar \pm 0.03 bar, 2 of $0-25$ bar \pm 0.075 bar). Two Coriolis mass flow meters ( $\pm 0.15 \%$ of lecture) measure refrigerant mass flow rates and two magnetic flow meters $( \pm 0.33 \%$ of lecture) the secondary fluids volumetric flow. Two digital wattmeters ( $\pm 0.5 \%$ lecture) measure the compressors power consumption. Data validation is made by comparing the heat transfer rates of the different fluids in the LT evaporator, in the cascade heat exchanger and in the condenser. Sanz-Kock et al. [14] details the data validation.

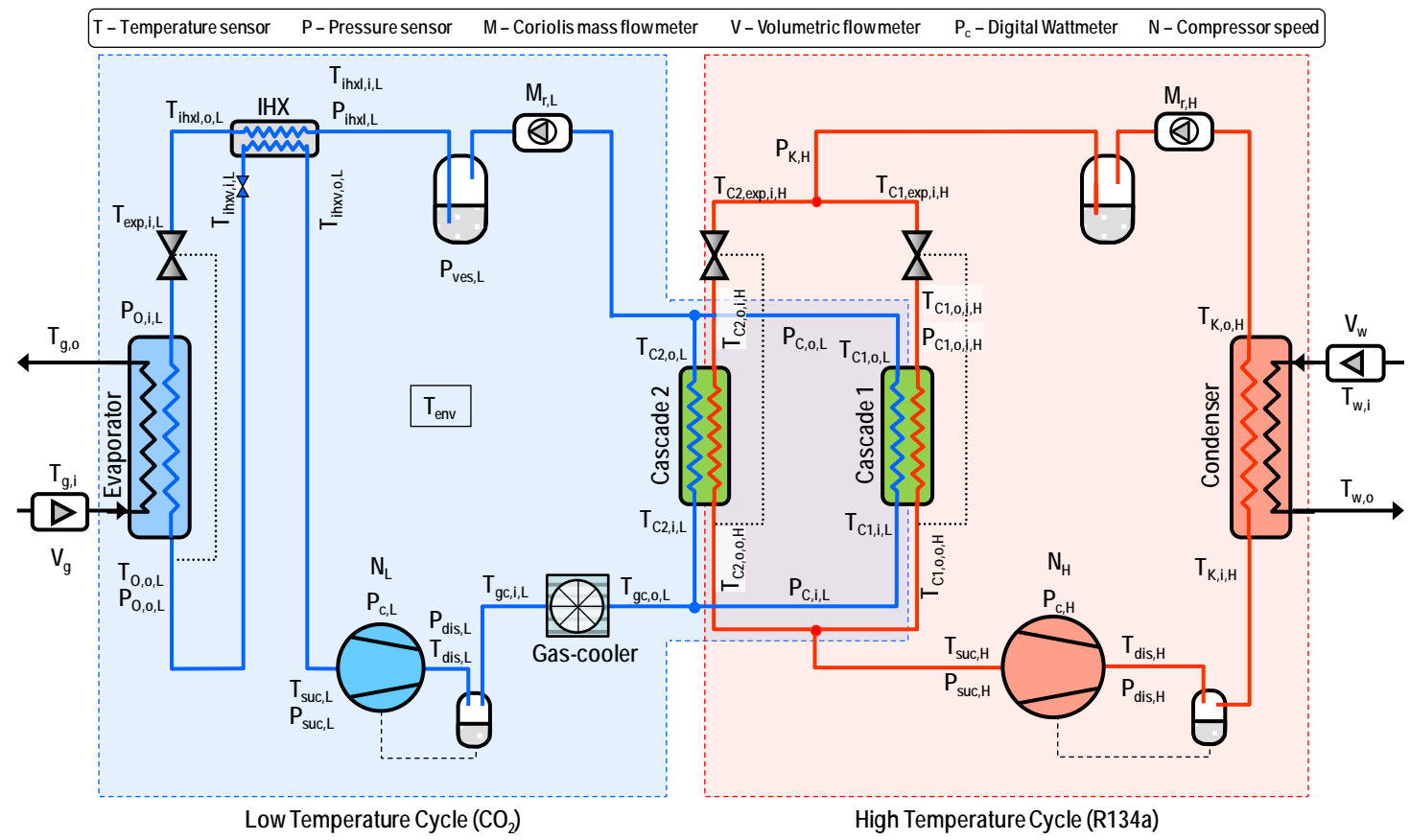

Figure 1. Experimental diagram of the test plant and measurements in each point

\section{Experimental procedure}

The test campaign used to evaluate the performance of the $\mathrm{HFC134a/CO}$ cascade refrigeration system working with and without IHX covered evaporating temperatures of the LT cycle from -40 to $-30{ }^{\circ} \mathrm{C}$ and $\mathrm{HT}$ condensing temperatures from 30 to $50^{\circ} \mathrm{C}$. Table 1 details the main reference parameters during the evaluation of the plant. For all the tests, the $\mathrm{CO}_{2}$ compressor operated at its nominal speed of $1450 \mathrm{rpm}$ and, for each test condition, the intermediate temperature level varied with HT compressor speed regulation. At least five steady-states (at different HT compressor speeds) were measured for each test 
condition, covering thus a wide range of intermediate conditions (LT condensing temperature / HT evaporating temperature). Each steady-state lasted at least 15 minutes, were the maximum allowed deviation in the evaporating and condensing temperatures was of $\pm 0.3^{\circ} \mathrm{C}$. In the tests the gas-cooler of the LT cycle was always kept on.

\section{Discussion of experimental results}

The internal heat exchanger directly modifies the operating conditions of the low-temperature cycle, as analysed by Llopis et al. [13] for the same plant, however, it also indirectly influences the high-temperature cycle and thus the global operation of the cascade system. This affirmation can be observed in the temperature-entropy diagram of the cycles presented in Figure 2, where the measured cycles of the cascade system are presented for a $\mathrm{LT}$ evaporating temperature of $-40{ }^{\circ} \mathrm{C}$ and a $\mathrm{HT}$ condensing temperature of $50^{\circ} \mathrm{C}$ with and without the $\mathrm{IHX}$ for a speed of the $\mathrm{HT}$ compressor of $1007.2 \mathrm{rpm}$. In Figure

2 , it can be observed that the use of the IHX introduces also modifications in the intermediate temperature level. Accordingly, first, we discuss the main modifications in the low-temperature cycle, then in the cascade heat exchanger and in the high-temperature cycle and finally we present the overall performance of the cascade system.

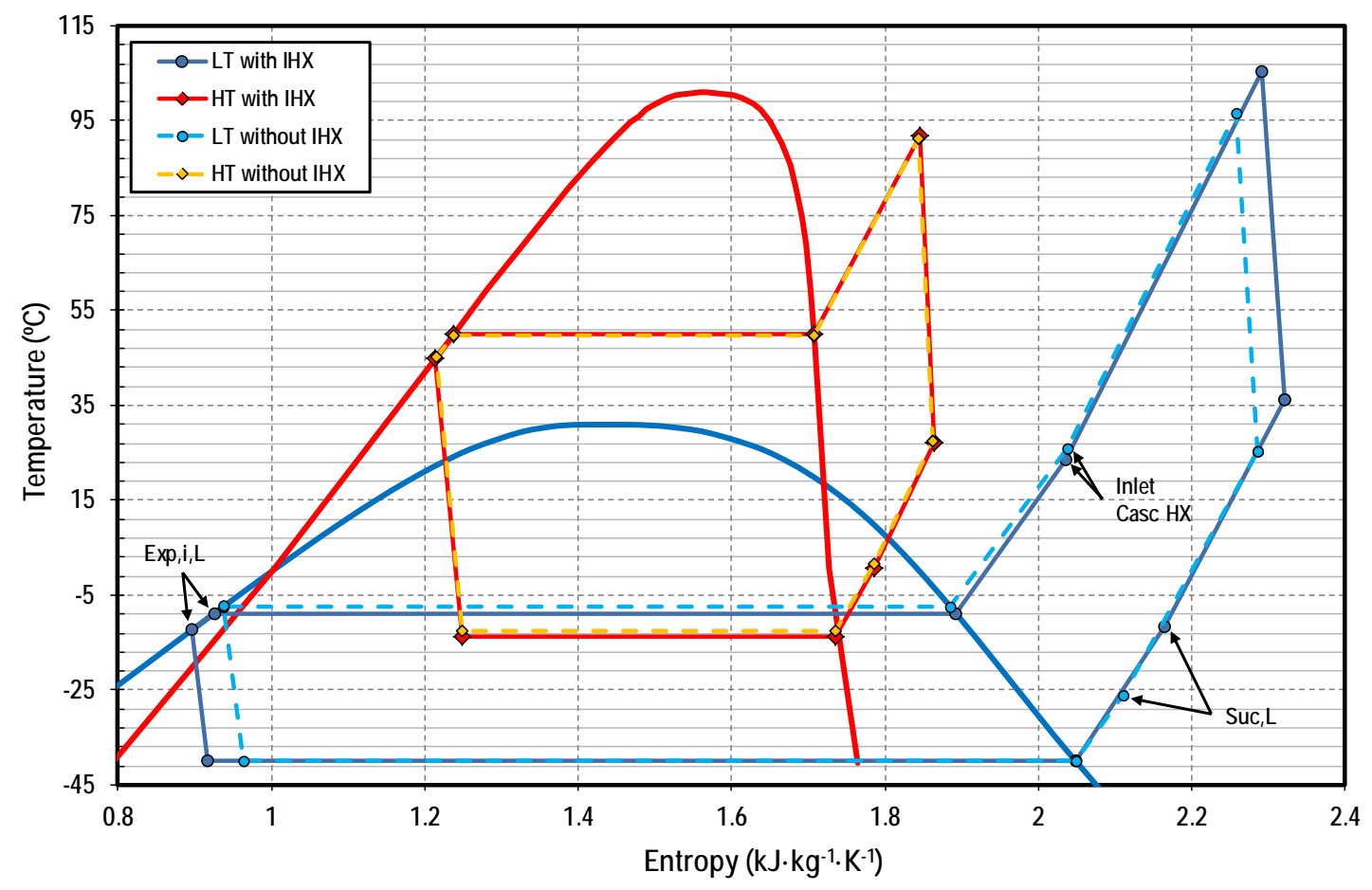

Figure 2. Ts diagrams of the cycles with and without $\mathrm{IHX} .\left(\mathrm{T}_{\mathrm{O}, \mathrm{L}}=-40.0^{\circ} \mathrm{C}, \mathrm{T}_{\mathrm{K}, \mathrm{H}}=50.0^{\circ} \mathrm{C}, \mathrm{N}_{\mathrm{H}}=1007.2 \mathrm{rpm}\right)$ 


\subsection{Modifications in the low temperature cycle}

The use of the IHX in the subcritical cycle of a cascade system brings about increments on the specific suction volume of the LT compressor, thus refrigerant mass flow rate in the LT cycle is reduced, Eq. (1); however the specific cooling capacity increases thanks to the subcooling achieved in the $\mathrm{IHX}$. For $\mathrm{CO}_{2}$ in subcritical operation, it was verified that the reduction of the mass flow was more important than the increase of the specific cooling capacity, resulting in reductions of capacity of the whole system, Eq. (2) [14]. Figure 3 compares the refrigerant mass flow rate of the LT cycle in different LT evaporating levels in a wide range of $L T$ condensing temperatures. The average reductions of the $L T$ refrigerant mass flow rate range from 4.7 to $6.2 \%$. Figure 4 presents the experimental capacity measured in all the tests, according to Eq. (2), where the inlet enthalpy to the evaporator has been evaluated considering the lamination process isenthalpic. Data regarding the three HT condensing levels is represented in Figure 4. The average reductions in capacity for all the test range, when using the $\mathrm{IHX}$, ranged from $1.1 \%$ at $-40{ }^{\circ} \mathrm{C}$ to $2.4 \%$ at $-30{ }^{\circ} \mathrm{C}$, they being lower than the reductions suffered by the mass flow rate. Obviously, from the point of view of the capacity, the use of the IHX will slightly reduce the capacity of the plant.

$$
\begin{gathered}
\dot{m}_{r, L}=\frac{\eta_{v, L}}{v_{s u c, L}} \cdot \dot{V}_{G, L} \\
\dot{Q}_{O, L}=\dot{m}_{r, L} \cdot\left(h_{O, o}-h_{O, i}\right)=\dot{m}_{r, L} \cdot q_{O, L}
\end{gathered}
$$

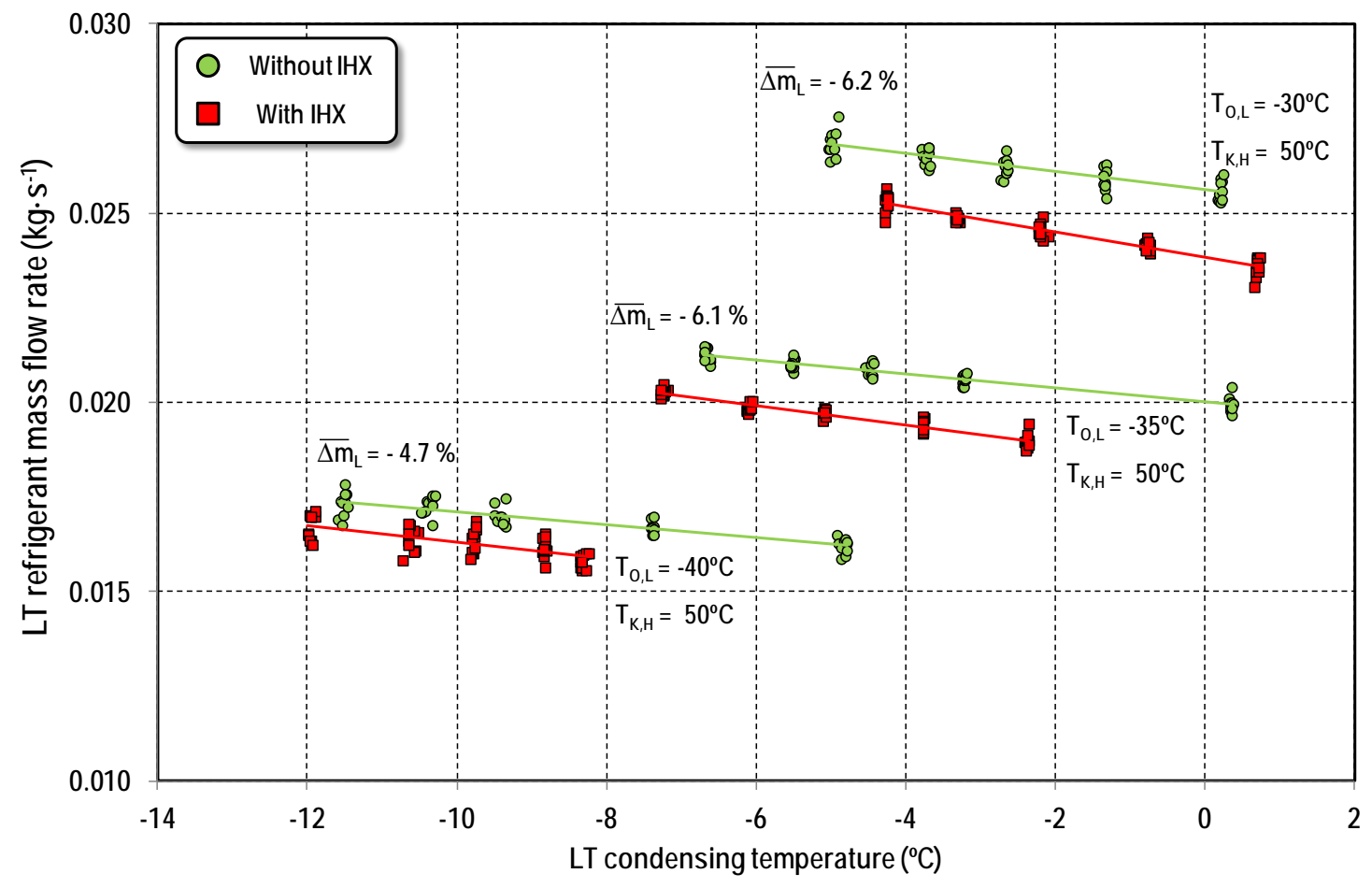


Figure 3. Low temperature refrigerant mass flow rate with and without $\mathrm{IHX}\left(\mathrm{T}_{\mathrm{K}, \mathrm{H}}=50^{\circ} \mathrm{C}\right)$

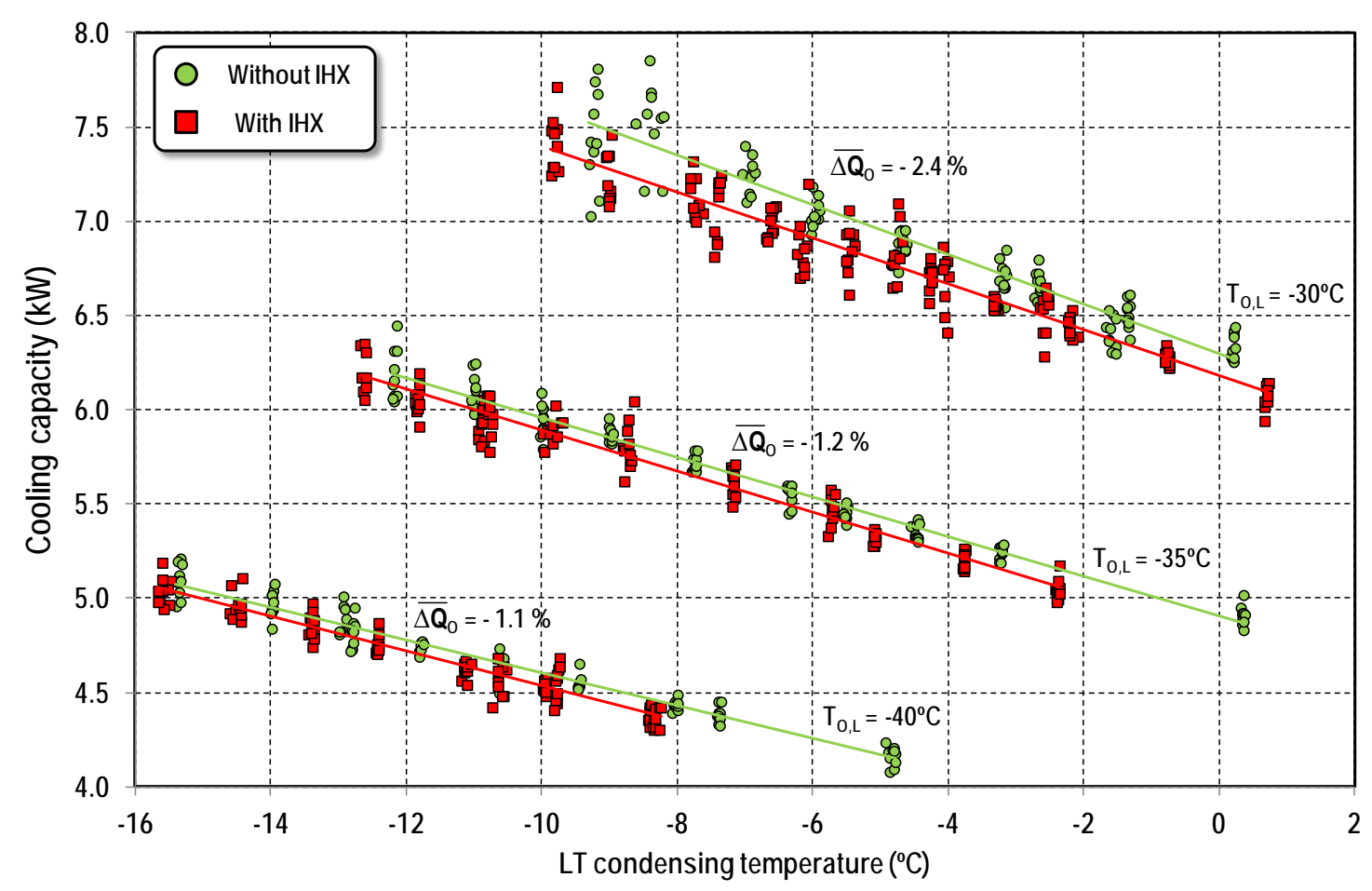

Figure 4. Cooling capacity with and without IHX

However, the reduction of the LT refrigerant mass flow rate has also influence in the cascade heat exchanger and thus in the HT refrigeration cycle. The use of the IHX reduces the mass flow but increases the LT compressor discharge temperature. Nonetheless, in this plant, the increment of the discharge temperature is avoided since it incorporates a gas-cooler at the exit of the compressor (Figure 1). The inlet temperature to the cascade heat exchanger depends on the thermal effectiveness of the gas-cooler, Eq. (3). For this plant in all the analysed range, its thermal effectiveness varied from $96.4 \%$ to $99.9 \%$, and it was independent of the use of the (Table 1). Accordingly, the inlet temperature of the vapour to the cascade heat exchanger was also independent of the use of the IHX, being the inlet temperature of the $\mathrm{CO}_{2}$ to the cascade heat exchanger similar to the environment temperature, as can be seen in Figure 2. The result is that when the IHX is used there is an effective reduction of the heat to be transferred in the cascade heat exchanger, caused by the reduction of the refrigerant mass flow in the LT cycle. Accordingly, the HT cycle is subjected to less cooling load, as presented in Figure 5. The average reductions of the heat to be transferred to the $\mathrm{HT}$ cycle ranged from $4.4 \%$ to $5.2 \%$. They slightly differ from the reductions of mass flow because the intermediate level (LT condensing or HT evaporating temperatures) is modified (Figure 2), as detailed in next subsection. 


$$
\varepsilon_{g c}=\frac{T_{g c, i}-T_{g c, o}}{T_{g c, i}-T_{e n v}}
$$

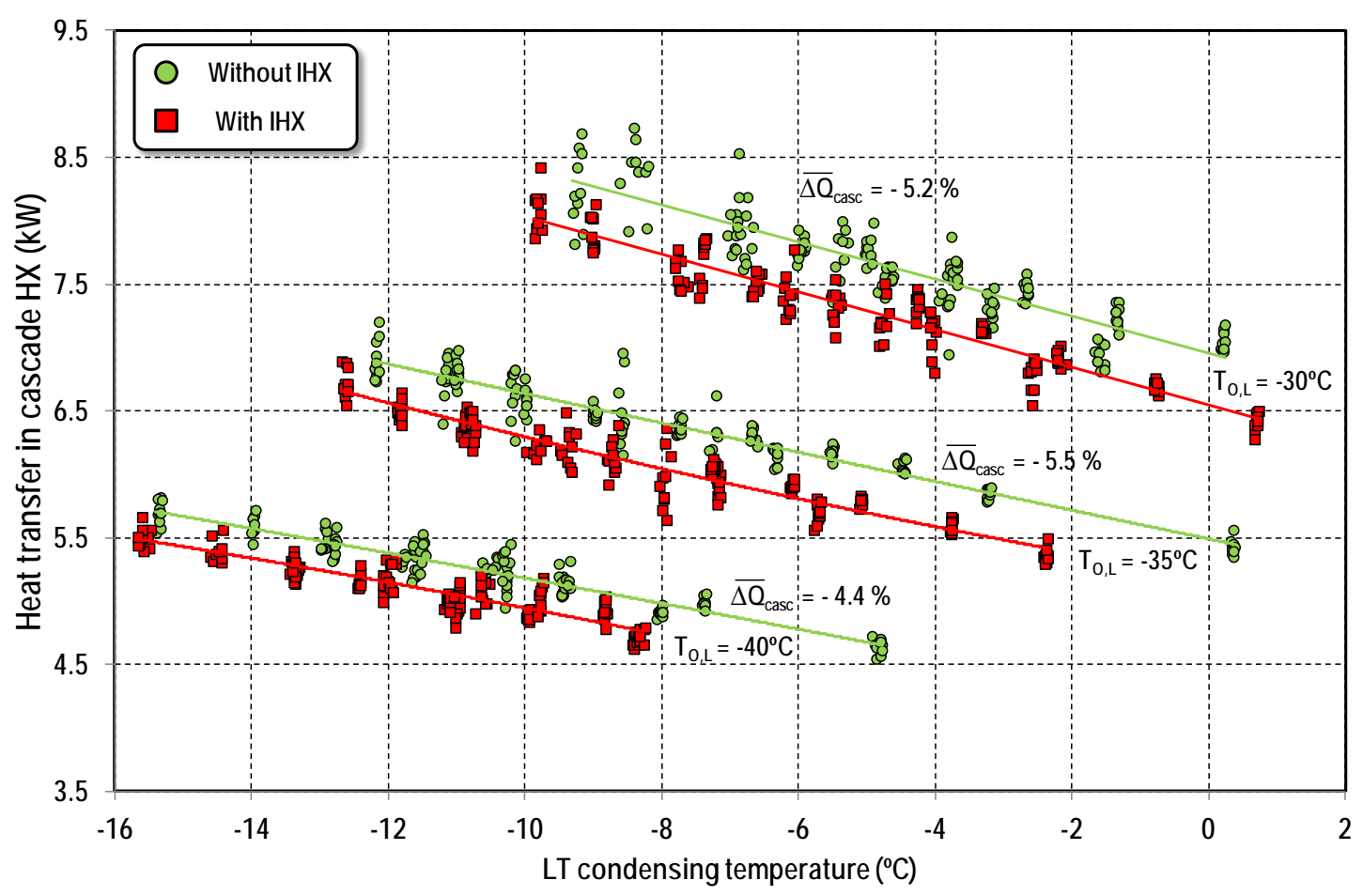

Figure 5. Heat transfer in the cascade heat exchanger with and without IHX

\subsection{Modifications in the cascade heat exchanger and the high temperature cycle}

The cascade heat exchanger is the thermal coupling between the LT cycle and the HT cycle, it acts as condenser of the LT cycle and evaporator of the HT cycle. Heat transfer in the cascade HT is evaluated using Eq. (4) for LT cycle condensation and with Eq. (5) for HT cycle evaporation, where the enthalpy values of the refrigerants at the inlet and exit of both cascade heat exchangers are averaged values. The average discrepancy between both heat transfer rates is of $2.7 \%$ working without $\mathrm{IHX}$ and $3.3 \%$ working with $\mathrm{IHX}$, as presented in [13].

$$
\begin{gathered}
\dot{Q}_{K, L}=\dot{m}_{r, L} \cdot\left(\frac{\left(h_{C 1, i, L}-h_{C 1, o, L}\right)+\left(h_{C 2, i, L}-h_{C 2, o, L}\right)}{2}\right)=\dot{m}_{r, L} \cdot q_{K, L} \\
\dot{Q}_{O, H}=\dot{m}_{r, H} \cdot\left(\frac{\left(h_{C 1, O, i, H}-h_{C 1, O, o, H}\right)+\left(h_{C 2, O, i, H}-h_{C 2, O, o, H}\right)}{2}\right)=\dot{m}_{r, H} \cdot q_{O, H}
\end{gathered}
$$

Neglecting heat losses to the environment in the cascade heat exchangers, the heat balance in the cascade heat exchanger relates the refrigerant mass flow rate of the HT cycle needed to absorb the heat 
rejection of the LT cycle in the cascade heat exchanger, Eq. (6). Since the heat rejection of the LT cycle decreases with the use of the IHX (Figure 5), the refrigerant mass flow rate of the HT is also reduced. This effect can be observed in Figure 6 for the operation of the plant at three evaporating levels (-30, -35 and $40{ }^{\circ} \mathrm{C}$ ) and a $\mathrm{HT}$ condensing temperature of $50^{\circ} \mathrm{C}$. For these cases, the reduction of the $\mathrm{HT}$ mass flow rate ranges from 3.4 to $4.9 \%$.

$$
\dot{m}_{r, H}=\frac{\dot{Q}_{K, L}}{q_{O, H}}
$$

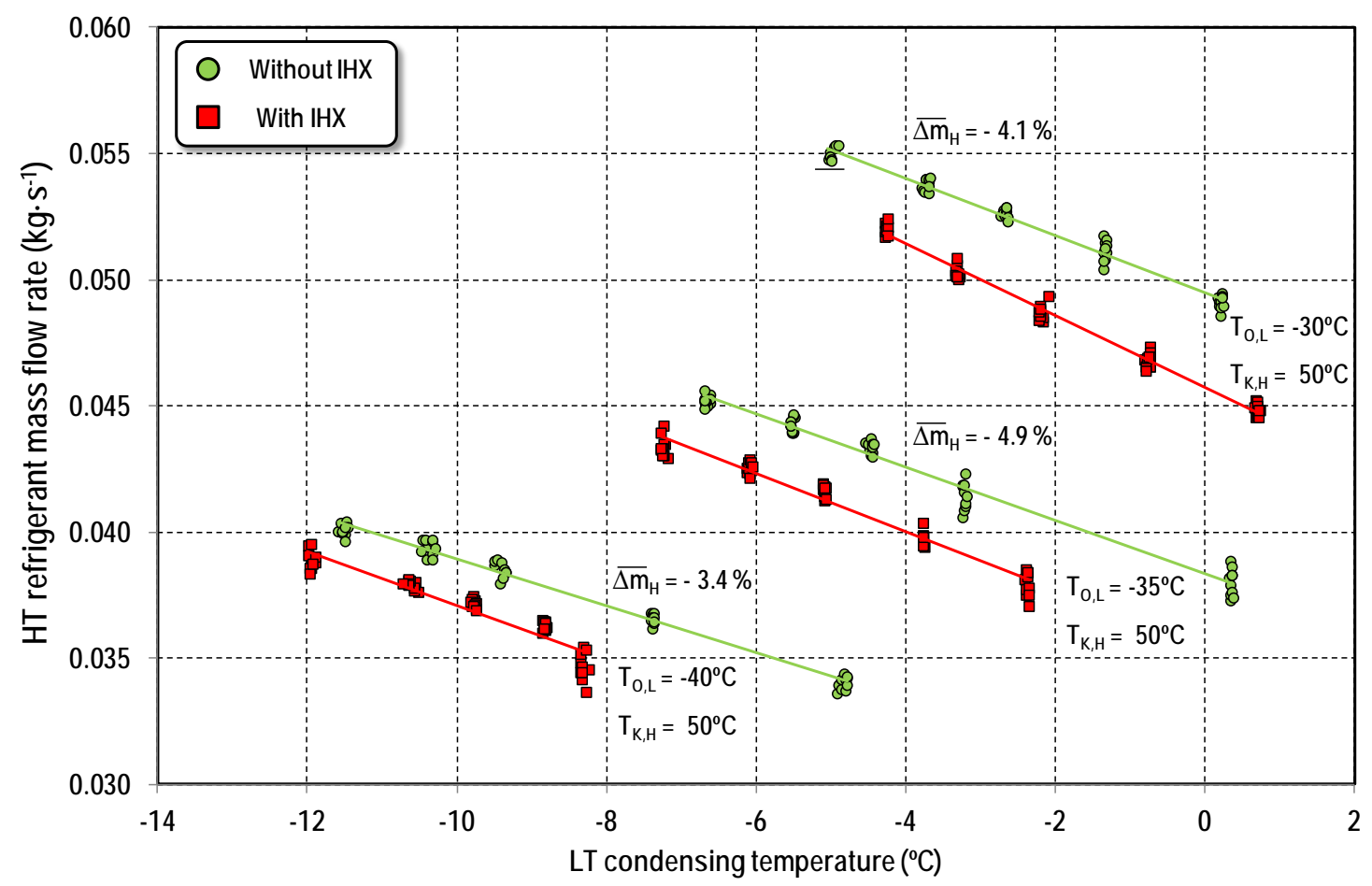

Figure 6. HT refrigerant mass flow rate with and without $\mathrm{IHX}\left(\mathrm{T}_{\mathrm{K}, \mathrm{H}}=50.0^{\circ} \mathrm{C}\right)$

As it can be seen in Figure 2, the use of the IHX scrolls down the intermediate level of the cascade system, reducing the HT evaporating temperature and the LT condensing level. It has been verified that the reduction of the intermediate level is independent of the use of the IHX, as observed in Figure 7, where the HT evaporating temperature is contrasted with the LT condensing level. For each evaporating level the phase change temperatures in the cascade heat exchanger are independent of the use of the $\mathrm{IHX}$. The temperature difference of the data to the continuous line $\left(T_{O, H}=T_{K, L}\right)$ corresponds to the temperature difference between condensation and evaporation in the cascade heat exchanger, Eq. (7).

$$
\Delta T_{\text {casc }}=T_{K, L}-T_{O, H}
$$




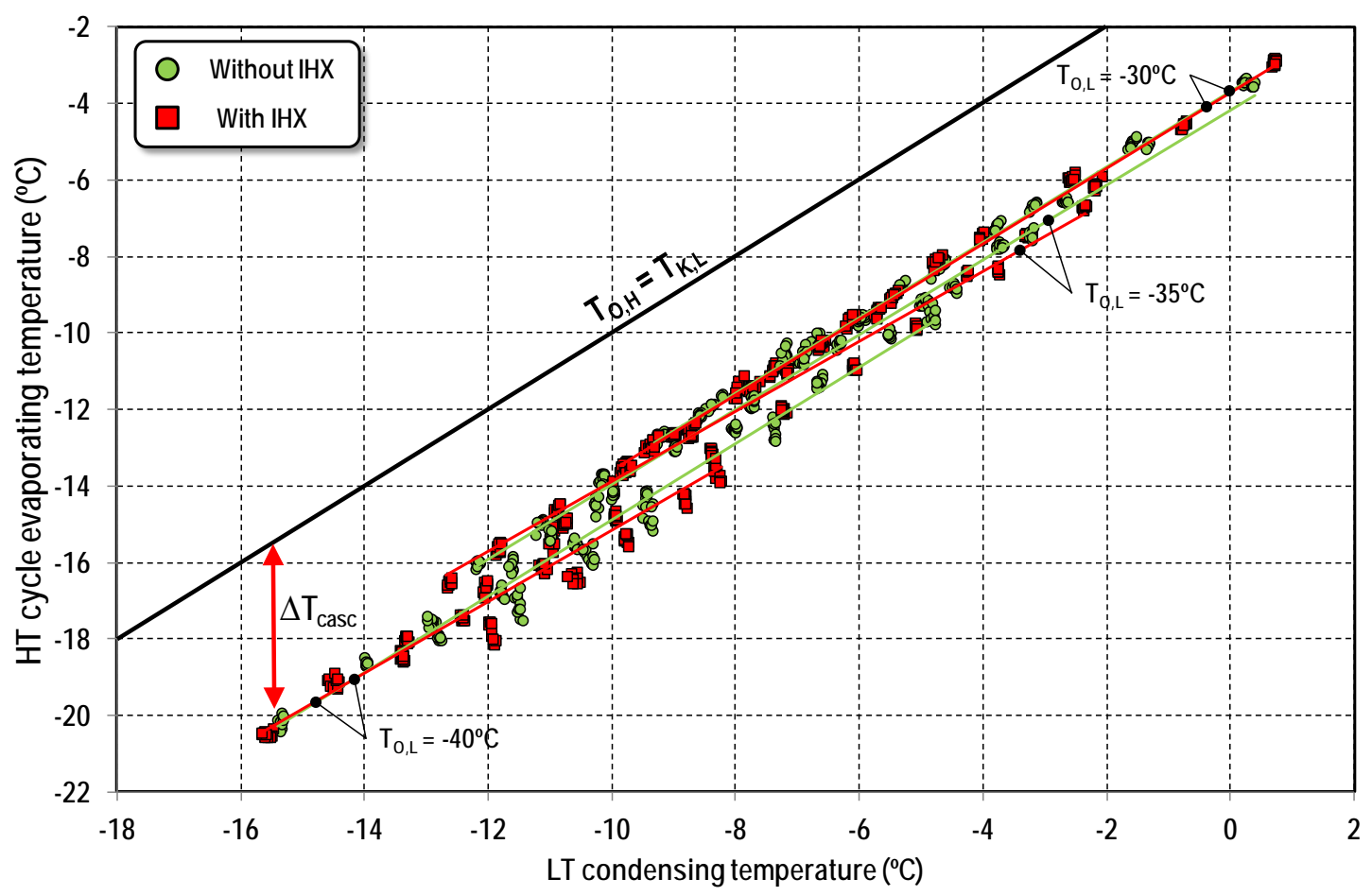

Figure 7. Temperature difference in cascade heat exchanger with and without IHX

Obviously, if there is a reduction of the heat to be transferred in the cascade heat exchanger (Figure 5), the heat transfer surface is the same and the temperature difference in the cascade heat exchanger remains constant (Figure 7), there will be a modification of the heat transfer characteristics in the cascade heat exchanger. That can be approximately analysed by evaluating the overall heat transfer coefficient in the cascade heat exchanger. For this comparison, that is presented in Figure 8 for three evaporating levels, it has been evaluated as done by Dopazo et al. [17] by referring it to the temperature difference in the cascade heat exchanger, Eq. (7).

$$
\bar{U}=\frac{\dot{Q}_{O, H}}{S_{\text {casc }} \cdot \Delta T_{\text {casc }}}
$$

As it can be observed in Figure 8, the use of the $\mathrm{IHX}$, causes reductions of the overall heat transfer coefficient in the cascade heat exchanger, being the measured reductions ranging from 7.0 to $8.6 \%$. Although it has not been extensively analysed, this reduction could be caused by the reductions of both refrigerant mass flow rates $\left(m_{L}, m_{H}\right)$ when the $\mathrm{IHX}$ is used. Accordingly, although the heat transfer in the cascade heat exchanger is reduced due to the use of the $\mathrm{IHX}$, this reduction is not translated directly to the improvement of the cycle, since there is a degradation of the heat transfer characteristics in the cascade heat exchanger that does not allow lowering the temperature difference in the cascade heat exchanger. 


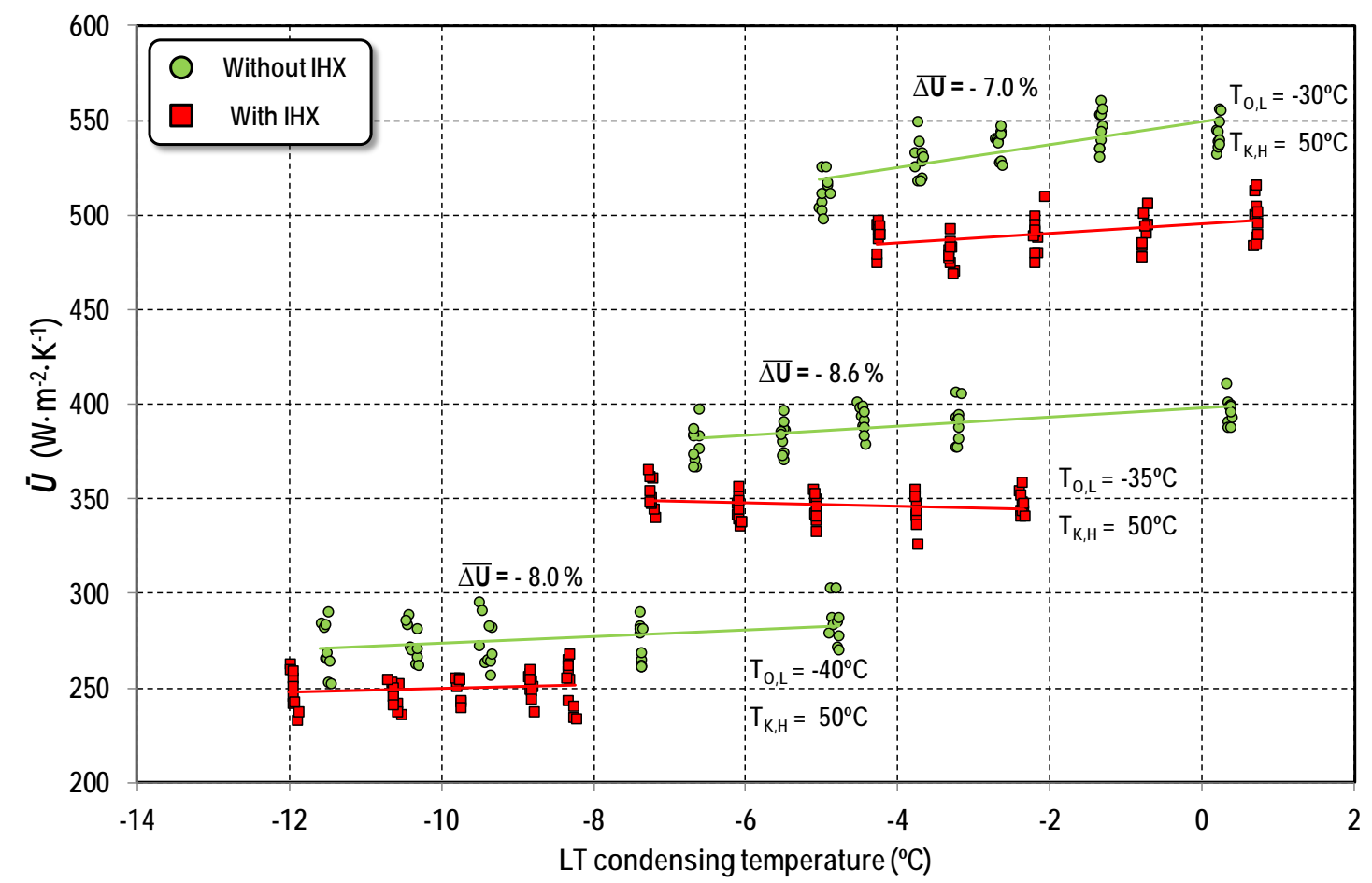

Figure 8. Overall heat transfer coefficient of cascade heat exchanger with and without $I H X\left(T_{K, H}=50.0^{\circ} \mathrm{C}\right)$

\subsection{Modifications of the cascade cycle}

All the modifications introduced by the use of the IHX can be summarized attending to the coefficient of performance of the cascade system, Eq. (9). It is the quotient of the cooling capacity provided by the LT cycle and the sum of the electrical power consumptions of the LT and HT compressors and the electrical fan of the gas-cooler $(75 \mathrm{~W})$.

$$
C O P=\frac{\dot{Q}_{O, L}}{P_{c, L}+P_{c, H}+P_{c, g c}}
$$

As detailed previously, there is a slight decrement of the capacity of the cycle due to the use of the IHX (Figure 4), mainly driven by the reduction of refrigerant mass flow rate in the low temperature cycle. This reduction of the mass flow rate has also effect on the power consumption of the LT compressor, as presented in Figure 9. For the operation at a $\mathrm{HT}$ condensing temperature of $50^{\circ} \mathrm{C}$ the reduction of this consumption is inside the range 0.92 to $1.60 \%$. The reduction of mass flow rate is not translated directly to the power consumption, since the increase of the $\mathrm{CO}_{2}$ specific suction volume increases the isentropic specific compression work. The most important reduction is observed at the HT compressor, which data for the operation at a HT condensing temperature are presented in Figure 10. In this case, since the heat to be transferred in the cascade condenser is reduced, it has a direct impact in the HT refrigerant mass 
flow rate (Figure 6) and thus in the power consumption of the compressor. In this case, the average measured reductions are between 3.05 to $4.97 \%$.

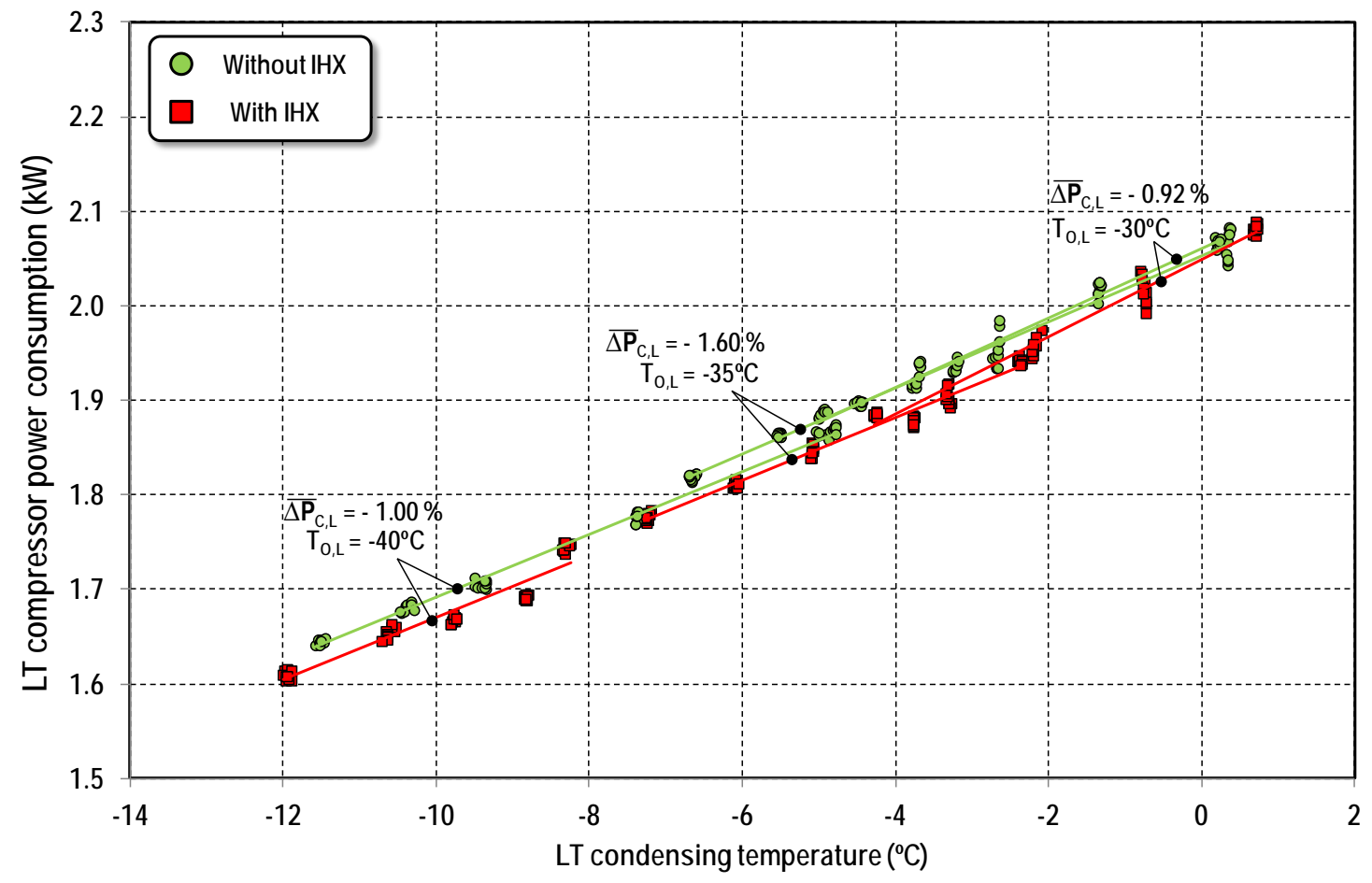

Figure 9. Low temperature compressor power consumption with and without IHX $\left(T_{K, H}=50.0^{\circ} \mathrm{C}\right)$

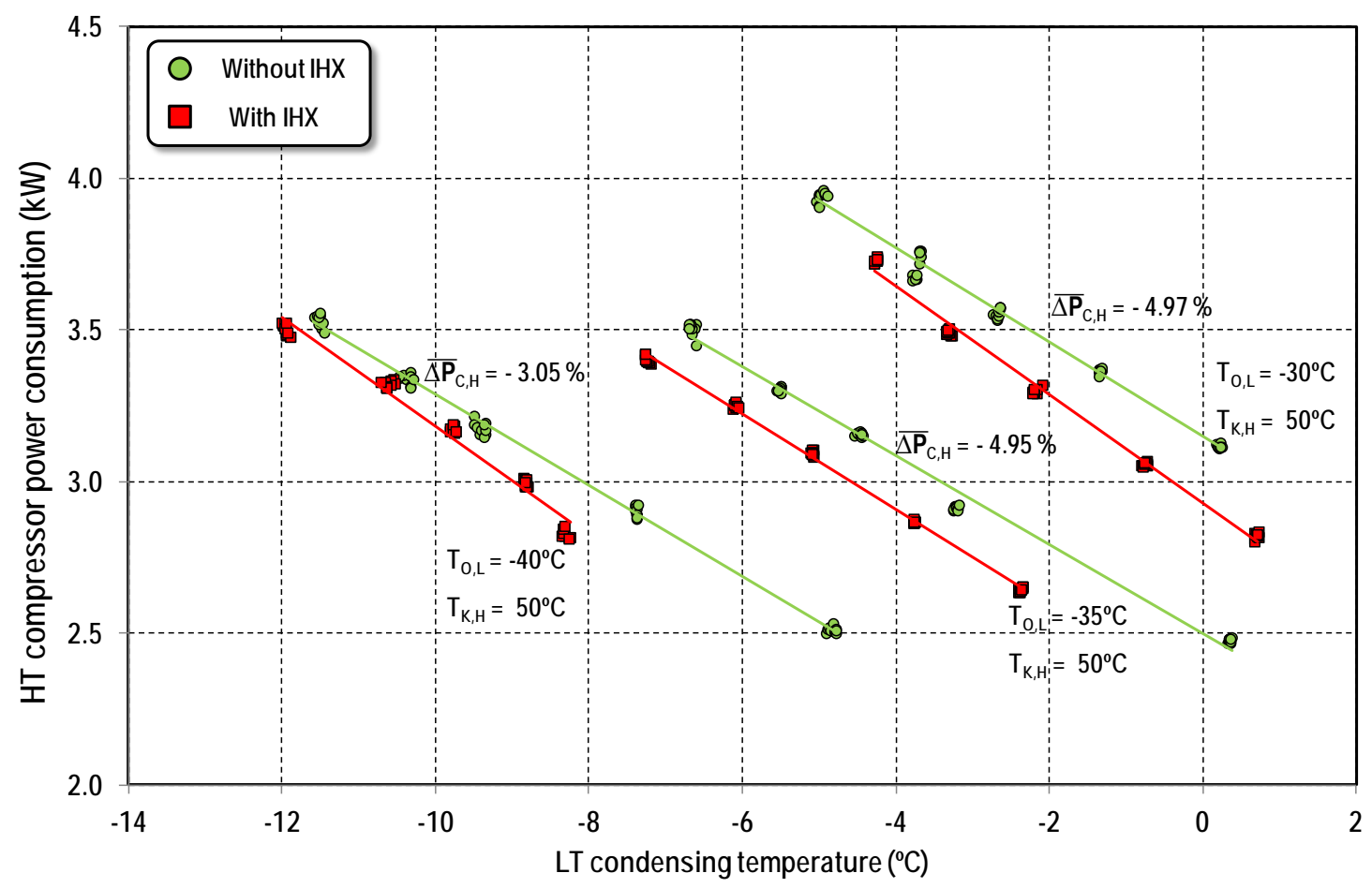


Figure 10. High temperature compressor power consumption with and without $\mathrm{IHX}\left(\mathrm{T}_{K, H}=50.0^{\circ} \mathrm{C}\right)$

Finally, the calculated COP from measured data with and without IHX are presented in Figure 11 for the operation at three LT evaporating levels $\left(-40,-35\right.$ and $\left.-30^{\circ} \mathrm{C}\right)$ and three $H T$ condensing levels $(30,40$ and $50^{\circ} \mathrm{C}$ ) for a wide range of intermediate temperatures. The variation of the intermediate level is achieved with variation of the speed of the HT compressor. As it can be observed, for all tested conditions, the introduction of the $\mathrm{IHX}$ in the $\mathrm{LT}$ temperature cycle brings improvements on the overall energy performance of the cascade system. The conclusion that can be extracted is that the reduction of the capacity due its use (Figure 4) is lower than the benefit obtained due to the reduction of the heat to be transferred in the cascade heat exchanger (Figure 5). Accordingly, its use is also beneficial from the point of view of energy efficiency.

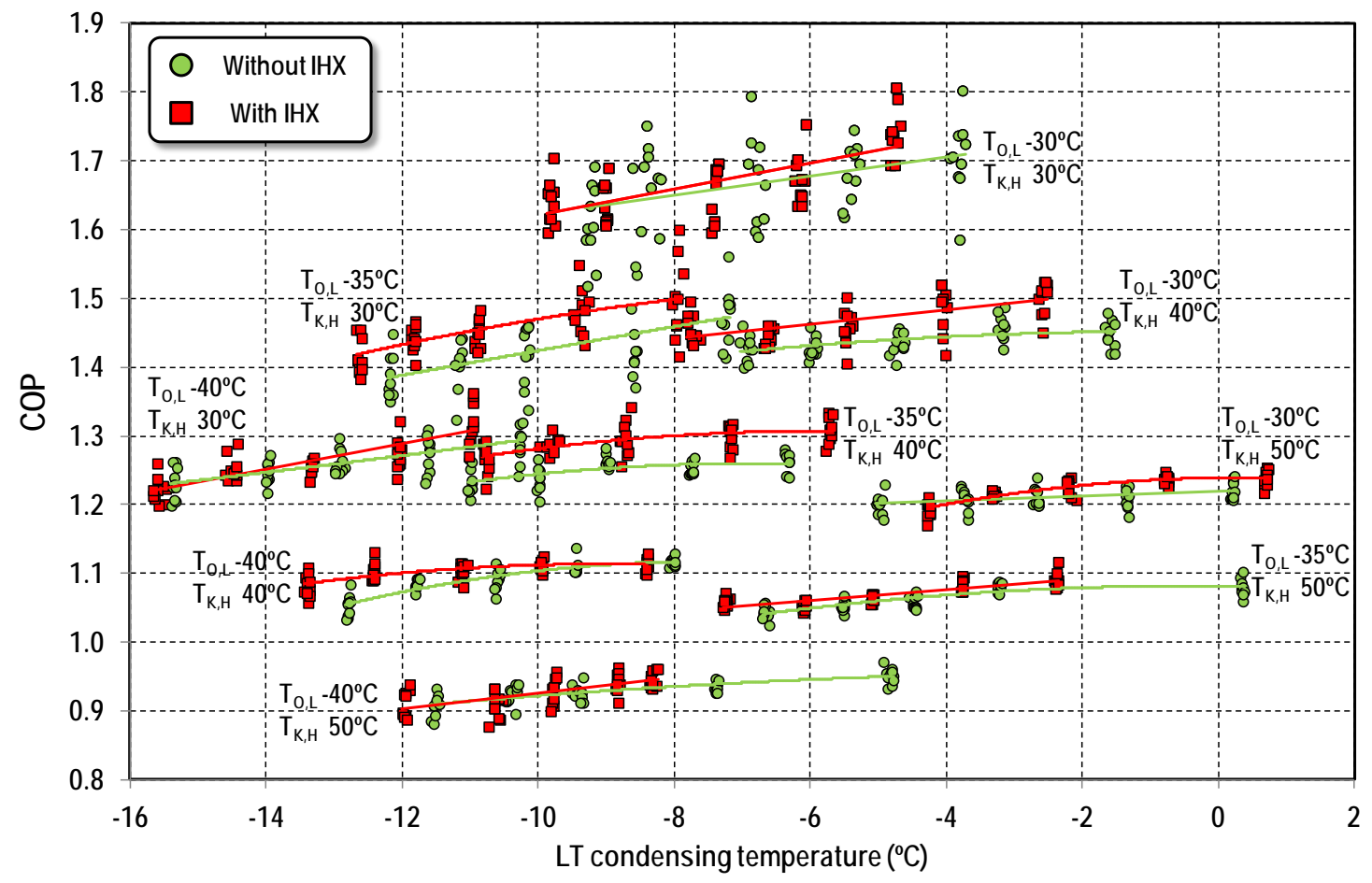

Figure 11. COP with and without IHX

\subsection{Comparison at the best conditions}

Finally, the main energy parameters of the cascade system using or not using the $\mathrm{IHX}$ are summarized: cooling capacity in Figure 12 and COP Figure 13. The data here considered corresponds to the condition at the maximum measured COP (Table 1). It needs to be mentioned that some of the values are not at the optimum (maximum COP) condition, since we could not reach them because of the security restrictions of 
the plant. Regarding COP, the maximum measured increment has been of $3.7 \%$ at $T_{O, L}=-35{ }^{\circ} \mathrm{C}$ and $T_{K, H}$ $=40^{\circ} \mathrm{C}$, but for the operation at $\mathrm{T}_{\mathrm{O}, \mathrm{L}}=-40^{\circ} \mathrm{C}$ and $\mathrm{T}_{\mathrm{K}, \mathrm{H}}=50^{\circ} \mathrm{C}$ a decrement of $0.5 \%$ has been registered. Nonetheless, in general the $\mathrm{IHX}$ does not reduce the overall performance of the cascade system. For cooling capacity, the maximum measured reduction has been of $4.1 \%$ at $\mathrm{T}_{\mathrm{O}, \mathrm{L}}=-30^{\circ} \mathrm{C}$ and $\mathrm{T}_{\mathrm{K}, \mathrm{H}}=50^{\circ} \mathrm{C}$. 

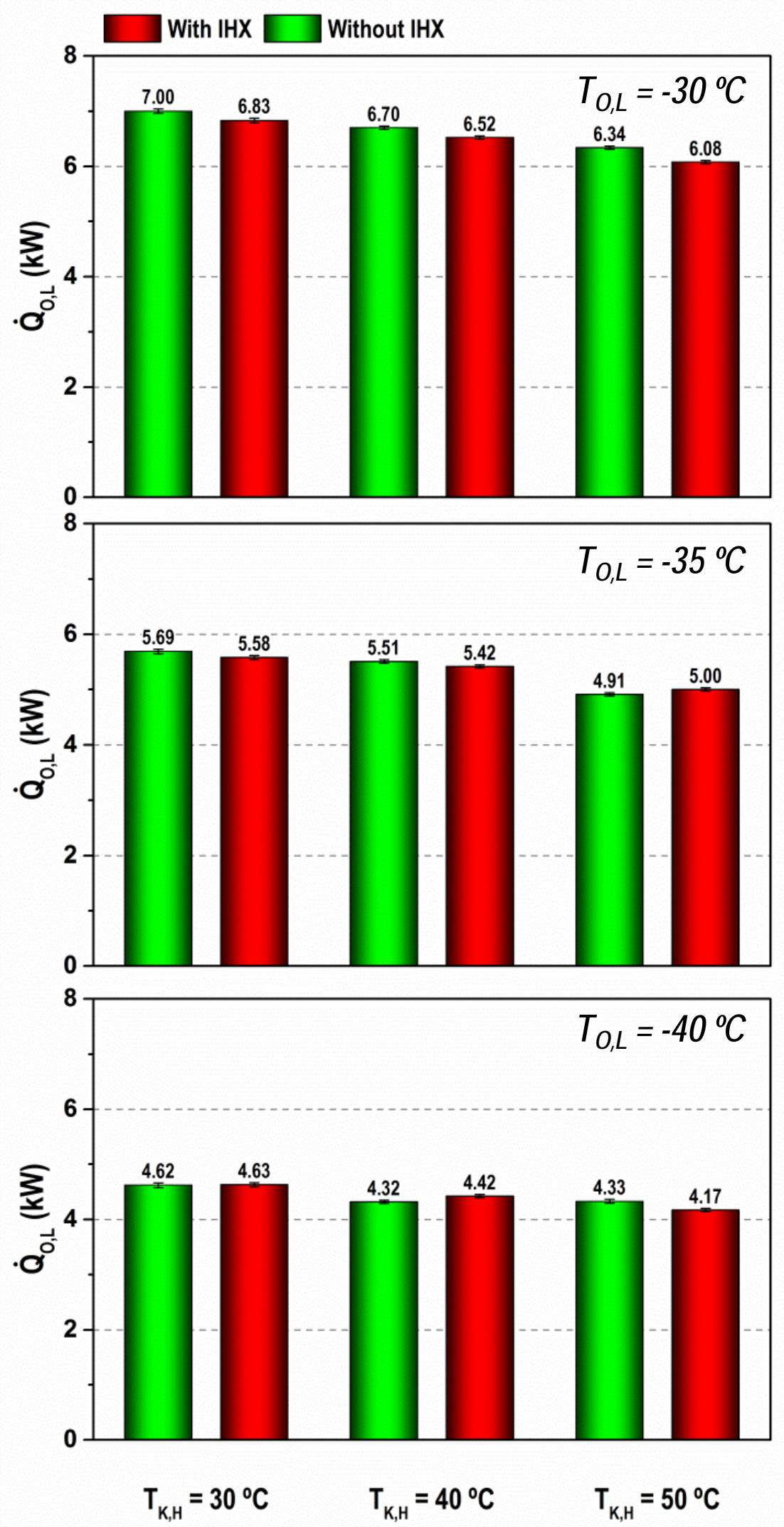

Figure 12. Cooling capacity with and without IHX at the maximum COP condition 

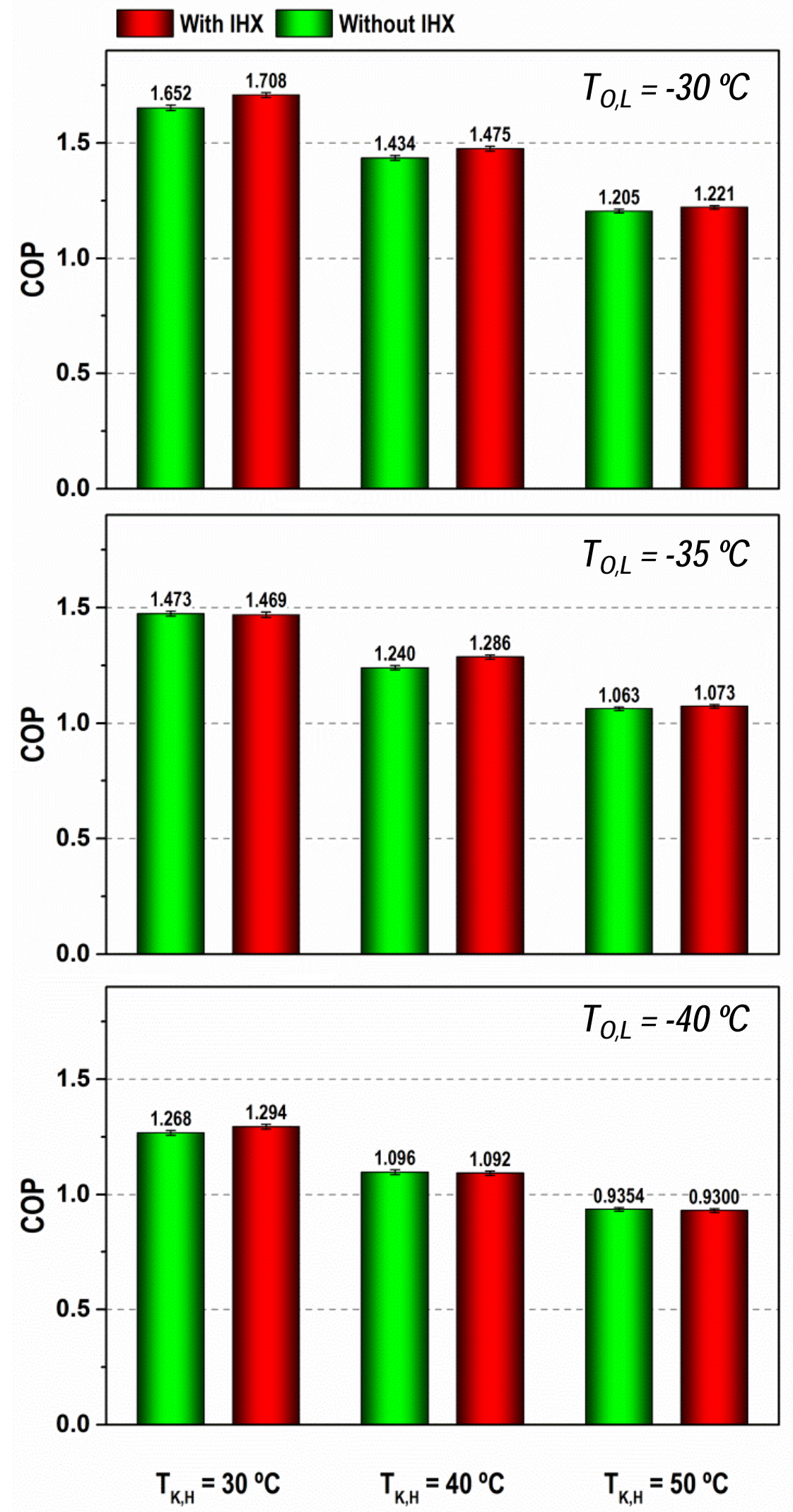

Figure 13. COP with and without IHX at the maximum COP condition 


\section{Conclusions}

This work presents the experimental evaluation of the influence of the use of an internal heat exchanger in a $\mathrm{CO}_{2}$ subcritical cycle in a whole $\mathrm{HFC} 134 \mathrm{a} / \mathrm{CO}_{2}$ cascade refrigeration system.

Previous theoretical studies predicted degradation of the main energy parameters for $\mathrm{CO}_{2}$ in subcritical operation and recommended not to use this element. This study verified this affirmation inside a wide range of operating conditions, measuring reductions of capacity between 2.4 to $1.1 \%$. However, the previous studies do not consider the operation of the subcritical cycle inside a cascade system.

This work extends the analysis to a whole $\mathrm{HFC} 134 \mathrm{a} / \mathrm{CO}_{2}$ cascade system. It has been measured that the use of the IHX reduces the heat to be transferred in the cascade heat exchanger (in average between 4.4 to $5.2 \%$ ), reducing thus the thermal load of the high temperature cycle. This heat load reduction allows reducing the high temperature refrigerant mass flow rate between 3.4 to $4.9 \%$. In addition, it has been observed that the temperature difference in the cascade heat exchanger remains independent of the use of the internal heat exchanger, but there is a degradation of the heat transfer characteristics in the cascade heat exchanger due to the reduction of the refrigerant flows.

For all the operation range, an improvement of the COP of the whole cascade system has been measured for all tested conditions inside a wide range of intermediate temperature levels. For the best performing intermediate level, the use of the internal heat exchanger in the $\mathrm{CO}_{2}$ cycle has offered a maximum increase of $\mathrm{COP}$ of $3.7 \%$ at $-35^{\circ} \mathrm{C}$ and $40^{\circ} \mathrm{C}$ of evaporating and condensing temperatures. However, at 40 and $50^{\circ} \mathrm{C}$ a decrement of $0.5 \%$ in COP has been measured.

According to the evaluation, we can affirm that the internal heat exchanger in the $\mathrm{CO}_{2}$ subcritical cycle in a whole cascade system is recommended if it incorporates a gas-cooler at the exit of the low temperature compressor. Since with a small reduction in capacity and a slight increment in COP, the plant benefits for the increment of the specific suction volume of the low temperature compressor, increasing thus the expected useful life of the plant. 


\section{Acknowledgements}

The authors gratefully acknowledge the Ministerio de Economía y Competitividad (project ENE201453760-R.7) and the Jaume I University (project P11B2015-66) for financing this research work. 


\section{References}

[1] European Commission, Regulation (EU) No 517/2014 of the European Parliament and of the Council of 16 April 2014 on fluorinated greenhouse gases and repealing Regulation (EC) No 842/2006., (2014).

[2] P. Bansal, A review - Status of $\mathrm{CO} 2$ as a low temperature refrigerant: Fundamentals and R\&D opportunities, Applied Thermal Engineering, 41 (2012) 18-29.

[3] L. Cecchinato, M. Corradi, S. Minetto, Energy performance of supermarket refrigeration and air conditioning integrated systems working with natural refrigerants, Applied Thermal Engineering, 48 (2012) 378-391.

[4] V. Sharma, B. Fricke, P. Bansal, Comparative analysis of various CO2 configurations in supermarket refrigeration systems, International Journal of Refrigeration, 46 (2014) 86-99.

[5] R. Llopis, D. Sánchez, C. Sanz-Kock, R. Cabello, E. Torrella, Energy and environmental comparison of two-stage solutions for commercial refrigeration at low temperature: Fluids and systems, Applied Energy, 138 (2015) 133-142.

[6] A. da Silva, E.P. Bandarra Filho, A.H.P. Antunes, Comparison of a R744 cascade refrigeration system with R404A and R22 conventional systems for supermarkets, Applied Thermal Engineering, 41 (2012) 30-35.

[7] R. Mastrullo, A.W. Mauro, S. Tino, G.P. Vanoli, A chart for predicting the possible advantage of adopting a suction/liquid heat exchanger in refrigerating system, Applied Thermal Engineering, 27 (2007) 2443-2448.

[8] P.A. Domanski, Theoretical evaluation of the vapor compression cycle with a liquid-line/suction-line heat heat exchanger, economizer, and ejector, in: National Institute of Science and Technology, Interagency Report 5606., National Institute of Standards and Technology, Gaithersburg, MD., 1995.

[9] C. Aprea, M. Ascani, F. de Rossi, A criterion for predicting the possible advantage of adopting a suction/liquid heat exchanger in refrigerating system, Applied Thermal Engineering, 19 (1999) 329336

[10] D. Sánchez, J. Patiño, R. Llopis, R. Cabello, E. Torrella, F.V. Fuentes, New positions for an internal heat exchanger in a $\mathrm{CO} 2$ supercritical refrigeration plant. Experimental analysis and energetic evaluation, Applied Thermal Engineering, 63 (2014) 129-139.

[11] E. Torrella, D. Sánchez, R. Llopis, R. Cabello, Energetic evaluation of an internal heat exchanger in a $\mathrm{CO}_{2}$ transcritical refrigeration plant using experimental data, International Journal of Refrigeration, 34 (2011) 40-49. 
[12] F.Z. Zhang, P.X. Jiang, Y.S. Lin, Y.W. Zhang, Efficiencies of subcritical and transcritical CO2 inverse cycles with and without an internal heat exchanger, Applied Thermal Engineering, 31 (2011) 432438.

[13] R. Llopis, C. Sanz-Kock, R. Cabello, D. Sánchez, E. Torrella, Experimental evaluation of an internal heat exchanger in a $\mathrm{CO} 2$ subcritical refrigeration cycle with gas-cooler, Applied Thermal Engineering, 80 (2015) 31-41.

[14] C. Sanz-Kock, R. Llopis, D. Sánchez, R. Cabello, E. Torrella, Experimental evaluation of a R134a/CO2 cascade refrigeration plant, Applied Thermal Engineering, 73 (2014) 39-48.

[15] R. Llopis, R. Cabello, D. Sánchez, E. Torrella, J. Patiño, J.G. Sánchez, Experimental evaluation of HCFC-22 replacement by the drop-in fluids HFC-422A and HFC-417B for low temperature refrigeration applications, Applied Thermal Engineering, 31 (2011) 1323-1331.

[16] R. Llopis, E. Torrella, R. Cabello, D. Sánchez, HCFC-22 replacement with drop-in and retrofit HFC refrigerants in a two-stage refrigeration plant for low temperature, International Journal of Refrigeration, 35 (2012) 810-816.

[17] J.A. Dopazo, J. Fernández-Seara, Experimental evaluation of a cascade refrigeration system prototype with $\mathrm{CO} 2$ and $\mathrm{NH} 3$ for freezing process applications, International Journal of Refrigeration, 34 (2011) 257-267. 
TABLES

\begin{tabular}{|c|c|c|c|c|c|c|c|c|c|c|c|c|c|}
\hline \multicolumn{14}{|c|}{ with IHX } \\
\hline$T_{0, L}$ & $T_{K, H}$ & $\mathrm{~T}_{\mathrm{K}, \mathrm{L}}$ & $\mathrm{T}_{\mathrm{O}, \mathrm{H}}$ & $\Delta \mathrm{T}_{\text {casc }}$ & $\mathbf{N}_{\mathbf{H}}$ & $\varepsilon_{\mathrm{IHX}}$ & $\varepsilon_{g c}$ & $\mathbf{Q}_{1 H X}$ & $Q_{K, L}$ & $\mathbf{Q}_{\mathrm{O}, \mathrm{L}}$ & $\mathbf{P}_{\mathrm{C}, \mathrm{L}}$ & $P_{C, H}$ & COP \\
\hline$\left({ }^{\circ} \mathrm{C}\right)$ & $\left({ }^{\circ} \mathrm{C}\right)$ & ('0) & $\left({ }^{\circ} \mathrm{C}\right)$ & $\left({ }^{\circ} \mathrm{C}\right)$ & (rpm) & (\%) & (\%) & (W) & (W) & (W) & (W) & (W) & $(-)$ \\
\hline-30.0 & 30.0 & -9.81 to -4.76 & -13.47 to -8.12 & 3.26 to 3.82 & 806 to 1209 & 84.4 to 94.0 & 97.2 to 99.8 & 146 to 265 & 7016 to 8419 & 6650 to 7710 & 1680 to 1890 & 2030 to 2860 & 1.61 to 1.71 \\
\hline-30.0 & 40.1 & -7.73 to -2.57 & -11.41 to -5.95 & 3.28 to 3.77 & 806 to 1209 & 83.1 to 86.5 & 96.1 to 98.9 & 189 to 287 & 6541 to 7779 & 6518 to 7125 & 1722 to 1956 & 2393 to 3171 & 1.42 to 1.47 \\
\hline-30.0 & 50.0 & -4.26 to 0.70 & -8.40 to -2.91 & 3.52 to 4.23 & 806 to 1209 & 75.7 to 78.5 & 96.4 to 98.5 & 216 to 305 & 6281 to 7459 & 5943 to 6801 & 1883 to 2089 & 2806 to 3744 & 1.18 to 1.22 \\
\hline-35.0 & 30.1 & -12.63 to -7.96 & -16.51 to -11.43 & 3.21 to 3.97 & 806 to 1209 & 89.3 to 98.8 & 98.1 to 99.5 & 149 to 239 & 5640 to 6889 & 5289 to 6256 & 1593 to 1763 & 1954 to 2724 & 1.39 to 1.47 \\
\hline-34.9 & 40.0 & -10.77 to -5.72 & -14.92 to -9.42 & 3.61 to 4.28 & 806 to 1209 & 86.9 to 91.0 & 97.6 to 99.9 & 184 to 260 & 5564 to 6498 & 5285 to 6011 & 1654 to 1826 & 2300 to 3019 & 1.25 to 1.29 \\
\hline-35.0 & 50.0 & -7.24 to -2.38 & -10.01 to -6.70 & 4.26 to 4.89 & 806 to 1209 & 82.6 to 83.7 & 97.3 to 99.2 & 204 to 272 & 5294 to 6118 & 4937 to 5546 & 1771 to 1947 & 2637 to 3425 & 1.04 to 1.07 \\
\hline-39.9 & 30.0 & -15.59 to -10.97 & -20.47 to -15.43 & 4.10 to 5.04 & 806 to 1209 & 92.9 to 99.8 & 99.2 to 99.9 & 144 to 201 & 4788 to 5665 & 4437 to 5091 & 1503 to 1652 & 1842 to 2567 & 1.20 to 1.29 \\
\hline-40.0 & 40.0 & -13.39 to -8.10 & -18.45 to -13.11 & 4.58 to 5.22 & 806 to 1209 & 89.4 to 90.7 & 98.8 to 99.7 & 150 to 204 & 4623 to 4903 & 4254 to 4903 & 1562 to 1727 & 2151 to 2860 & 1.06 to 1.09 \\
\hline-40.0 & 50.0 & -11.95 to -8.32 & -17.79 to -13.61 & 4.93 to 6.25 & 1007 to 1310 & 81.4 to 83.9 & 97.3 to 98.6 & 138 to 182 & 4569 to 5335 & 4266 tp 4772 & 1604 to 1749 & 2815 to 3527 & 0.89 to 0.93 \\
\hline \multicolumn{14}{|c|}{ Operation without IHX } \\
\hline-30.0 & 30.2 & -9.23 to 3.82 & -12.71 to -7.25 & 3.28 to 3.71 & 806 to 1209 & - & 94.7 to 95.6 & & 6944 to 8733 & 6357 to 7818 & 1706 to 1953 & 2043 to 2912 & 1.58 to 1.67 \\
\hline-30.0 & 40.1 & -6.93 to -1.59 & -10.68 to -5.00 & 3.31 to 3.90 & 806 to 1209 & - & 97.2 to 99.3 & - & 6816 to 8054 & 6302 to 7396 & 1799 to 1995 & 2430 to 3286 & 1.41 to 1.43 \\
\hline-30.0 & 50.1 & -4.98 to 0.21 & -9.17 to -3.43 & 3.57 to 4.28 & 907 to 1310 & - & 95.5 to 98.9 & - & 6971 to 7987 & 6255 to 7175 & 1862 to 2073 & 3112 to 3962 & 1.18 to 1.20 \\
\hline-34.9 & 30.0 & -12.17 to -7.23 & -16.02 to -10.57 & 3.08 to 4.03 & 806 to 1209 & - & 97.3 to 99.9 & - & 5996 to 7202 & 5471 to 6410 & 1631 to 1804 & 1981 to 2746 & 1.38 to 1.47 \\
\hline-35.0 & 40.1 & -11.00 to -6.34 & -15.29 to -10.28 & 3.86 to 4.42 & 907 to 1310 & - & 98.6 to 99.9 & - & 6043 to 6978 & 5427 to 6218 & 1661 to 1843 & 2525 to 3271 & 1.22 to 1.24 \\
\hline-35.0 & 50.0 & -6.66 to 0.35 & -11.29 to -3.50 & 3.75 to 4.75 & 705 to 1209 & - & 97.3 to 99.4 & - & 5349 to 6391 & 4832 to 5622 & 1814 to 2084 & 2469 to 3521 & 1.03 to 1.06 \\
\hline-40.0 & 30.1 & -15.35 to -10.27 & -20.15 to -14.43 & 4.00 to 5.02 & 806 to 1209 & - & 99.1 to 99.9 & - & 4950 to 5823 & 4432 to 5173 & 1540 to 1695 & 1877 to 2589 & 1.21 to 1.27 \\
\hline-40.0 & 40.1 & -12.79 to -8.02 & -17.96 to -12.49 & 4.38 to 5.26 & 806 to 1209 & - & 99.1 to 99.9 & - & 4865 to 5589 & 4374 to 4917 & 1620 to 1764 & 2185 to 2920 & 1.04 to 1.10 \\
\hline-40.0 & 50.0 & -11.52 to -4.83 & -17.09 to -9.52 & 4.37 to 6.06 & 806 to 1410 & - & 97.6 to 99.7 & - & 4544 to 5534 & 4081 to 4839 & 1641 to 1875 & 2503 to 3558 & 0.89 to 0.94 \\
\hline
\end{tabular}

Table 1. Reference parameters of the experimental evaluation of the cascade with and without IHX 